\title{
RESEARCH
}

Open Access

\section{BMSC-derived extracellular vesicles intervened the pathogenic changes of scleroderma in mice through miRNAs}

\author{
Jiahui $\mathrm{Jin}^{1+}{ }^{1}$, Qingjian $\mathrm{Ou}^{2 \dagger}{ }^{2}$, Zhe Wang ${ }^{3}$, Haibin Tian², Jing-Ying X ${ }^{2}$, Furong Gao ${ }^{2}$, Shuqin $\mathrm{Hu}^{3}$, Jie Chen ${ }^{3}$,
}

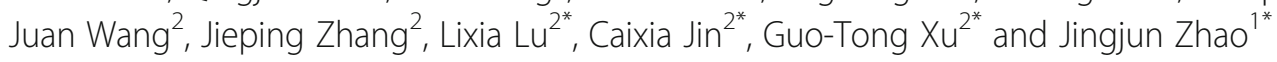

\begin{abstract}
Background: Systemic sclerosis (SSc) is a disease that features severe fibrosis of the skin and lacks effective therapy. Bone marrow mesenchymal stem cell (BMSC)-derived extracellular vesicles (EVs) are potential stem cell-based tools for the treatment of SSC.

Methods: BMSCs were isolated from the bone marrow of mice and identified with surface markers according to multilineage differentiation. EVs were isolated from the BMSC culture medium by ultracentrifugation and identified with a Nanosight NS300 particle size analyzer, transmission electron microscopy (TEM), and western blot. The microRNAs (miRNAs) of BMSC-derived EVs (BMSC-EVs) were studied via miRNA sequencing (miRNA-seq) and bioinformatic analysis. An SSc mouse model was established via subcutaneous bleomycin (BLM) injection, and the mice were treated with BMSCs or BMSC-derived EVs. Skin tissues were dissociated and analyzed with H\&E staining, RNA sequencing (RNA-seq), western blot, and immunohistochemical staining.

Results: Evident pathological changes, like fibrosis and inflammation, were induced in the skin of BLM-treated mice. BMSCs and BMSC-EVs effectively intervened such pathological manifestations and disease processes in a very similar way. The effects of the BMSC-EVs were found to be caused by the miRNAs they carried, which were proven to be involved in regulating the proliferation and differentiation of multiple cell types and in multiple EV-related biological processes. Furthermore, TGF- $\beta 1$-positive cells and a-SMA-positive myofibroblasts were significantly increased in the scleroderma skin of BLM-treated mice but evidently reduced in the scleroderma skin of the EVtreated SSc group. In addition, the numbers of mast cells and infiltrating macrophages and lymphocytes were evidently increased in the skin of BLM-treated mice but significantly reduced by EV treatment. In line with these observations, there were significantly higher mRNA levels of the inflammatory cytokines $\|6\|$,10 , and Tnf-a in SSC mice than in control mice, but the levels decreased following EV treatment. Through bioinformatics analysis, the TGF $\beta$ and WNT signaling pathways were revealed to be closely involved in the pathogenic changes seen in mouse
\end{abstract}

\footnotetext{
*Correspondence: lulixia@tongji.edu.cn; jincx@tongji.edu.cn;

gtxu@tongji.edu.cn; zhaojingjun2015@aliyun.com

${ }^{+}$Jiahui Jin and Qingjian Ou are co-first authors

2Department of Ophthalmology of Shanghai Tenth People's Hospital, and

Laboratory of Clinical Visual Science of Tongji Eye Institute, School of

Medicine, Tongji University, Shanghai 200072, China

'Department of Dermatology, Tongji Hospital, School of Medicine, Tongji

University, Shanghai 200065, China

Full list of author information is available at the end of the article
}

\section{$\triangle B M C$}

(c) The Author(s). 2021 Open Access This article is licensed under a Creative Commons Attribution 4.0 International License, which permits use, sharing, adaptation, distribution and reproduction in any medium or format, as long as you give appropriate credit to the original author(s) and the source, provide a link to the Creative Commons licence, and indicate if changes were made. The images or other third party material in this article are included in the article's Creative Commons licence, unless indicated otherwise in a credit line to the material. If material is not included in the article's Creative Commons licence and your intended use is not permitted by statutory regulation or exceeds the permitted use, you will need to obtain permission directly from the copyright holder. To view a copy of this licence, visit http://creativecommons.org/licenses/by/4.0/ The Creative Commons Public Domain Dedication waiver (http://creativecommons.org/publicdomain/zero/1.0/) applies to the data made available in this article, unless otherwise stated in a credit line to the data. 
SSc, and these pathways could be therapeutic targets for treating the disease.

Conclusions: BMSC-derived EVs could be developed as a potential therapy for treating skin dysfunction in SSc, especially considering that they show similar efficacy to BMSCs but have fewer developmental regulatory requirements than cell therapy. The effects of EVs are generated by the miRNAs they carry, which alleviate SSc pathogenic changes by regulating the WNT and TGF $\beta$ signaling pathways.

Keywords: Scleroderma, Fibrosis, Bone marrow mesenchymal stem cell, Extracellular vesicles

\section{Introduction}

Scleroderma (also known as systemic sclerosis, SSc) is an autoimmune connective tissue disease with unknown etiology and is characterized by three hallmark characteristics (vasculopathy, immune dysfunction, and fibroblast dysfunction) that which results in excessive accumulation of collagen and fibrosis in the skin and visceral organs $[1,2]$. Since there is no effective therapy, scleroderma often causes severe disability and even death $[3,4]$. Therefore, in-depth studies on the etiology of and effective treatments for scleroderma are necessary to improve the quality of life and life expectancy of patients.

Inflammation and vascular injury are reported to drive the autoimmune response and precede fibrosis in the initial stages of SSc $[5,6]$. This fibrosis is regulated by a combination of autocrine and paracrine profibrotic mediators, such as transforming growth factor- $\beta 1$ (TGF$\beta 1$ ), interleukin 4 (IL-4), interleukin 13 (IL-13), and interleukin 10 (IL-10). These mediators secreted by macrophages and monocytes promote tissue-resident fibroblasts to differentiate into myofibroblasts and enhance the production of collagen and other extracellular matrix (ECM) components by local fibroblasts and $\alpha$-smooth muscle actin $(\alpha-S M A)$-positive myofibroblasts in the affected organs [6-8]. Although SSc is considered an autoimmunity disease, toxin exposure and viral infection can also induce its occurrence and development. Subcutaneous injection of bleomycin (BLM) can induce skin fibrosis in mice that is similar to that seen in human SSc, including dermal fibrosis and abnormalities in ECM deposition, and this model is the most widely used preclinical animal model in antifibrotic research $[9,10]$.

Many regenerative medical therapies, such as mesenchymal stem cell (MSC) transplantation, have been explored for relieving the symptoms of or curing this difficult disease [11]. Alexandre et al. reported that transplanted allogeneic or xenogeneic bone marrow MSCs (BMSCs) demonstrated similar antifibrotic therapeutic effects in SSc [12]. Our previous report also showed that transplanted BMSCs or genetically engineered BMSCs attenuated skin fibrosis and reactive oxygen species (ROS)-induced apoptosis in the BLM- induced murine SSc model [10]. However, the number of colony-forming units in and the differentiation efficiency of the MSCs in the SSc injury site were relatively low. MSCs may exert their effects not through their differentiation but through paracrine mechanisms, such as extracellular vesicles (EVs), which contain cytokines, signaling lipids, and regulatory microRNAs (miRNAs) involved in cellular communication [13-15]. Recently, EVs, which are released by the outward budding of various types of cells (including MSCs), have been identified to contain major paracrine factors and thus could be appealing candidates as vectors for cell therapy [13, 14]. Intracellular delivery of EVs has been demonstrated for a number of different cell types and allows the functional utilization of the delivered miRNAs [16]. EVs have been implicated in the regenerative effects of MSCs in a wide variety of tissues, including skin, muscle, lung and vascular tissues [17-20]. MSC-derived EVs have also shown therapeutic potential in fibrotic diseases, such as renal fibrosis, corneal fibrosis, myocardial fibrosis, and hepatic fibrosis [21-23]. However, it is still unclear whether BMSC-derived EVs can mediate skin fibrosis in SSc.

In the present study, as a continuation of previous studies, we investigated the effects of subcutaneous injection of BMSC-derived EVs as a treatment for BLMinduced SSc mice and the underlying mechanism. BMSC-derived EVs significantly relieved fibrosis and inflammation in the skin, similar to the effects of BMSC transplantation. We also identified a group of specific miRNAs in BMSC-derived EVs. Multidimensional bioinformatics analysis suggested that these miRNAs contribute to the inhibition of $\alpha$-SMA expression and collagen deposition, as well as fibroblast/myofibroblast transition-induced fibrosis and inflammation. Therefore, BMSC-derived EVs could be a potential therapeutic strategy for alleviating inflammation and skin fibrosis in patients with SSc.

\section{Methods}

\section{Experimental animals}

All procedures using animal subjects were performed in accordance with the Guide for the Care and Use of 
Laboratory Animals, and the experiments were approved and performed following the guidelines of the Institute of Laboratory Animal Resources, Tongji University. Female C57BL/6 mice were obtained from Shanghai SLAC Laboratory Animal Co., Ltd. (China) and used in this study. Skin samples for molecular and histologic analyses were obtained at the time of euthanasia.

\section{BMSC isolation and culture}

BMSCs were isolated from the bone marrow of the femurs and tibias of mice (4 weeks old). The BMSCs were cultured in $\alpha$-MEM medium (SH30265.01, HyClone, Thermo Fisher Scientific, USA) supplemented with 15\% fetal bovine serum (FBS; 10091148, Thermo Fisher Scientific, USA) and $100 \mathrm{U} / \mathrm{mL}$ penicillin-streptomycin solution (10378016, Thermo Fisher Scientific, USA). The BMSCs were passaged when they reached $80 \%$ confluence. BMSCs in passage 3 were used in the analysis and for the production of EVs.

\section{Flow cytometry analysis}

BMSCs in passage 3 were used for flow cytometry analysis. Flow cytometry analysis of BMSC surface markers was performed as follows. BMSCs were suspended in phosphate-buffered saline (PBS; E607008-0500, Sangon Biotech, China) at a final concentration of $1 \times 10^{6} / \mathrm{mL}$. Then, monoclonal antibodies and the isotype control were added to $100 \mu \mathrm{L}$ cell suspensions and incubated for $60 \mathrm{~min}$ at $4{ }^{\circ} \mathrm{C}$. The cell suspensions were centrifuged at $2000 \mathrm{rpm}$ for $3 \mathrm{~min}$ to remove the antibodies and washed with PBS 3 times. Finally, $500 \mu \mathrm{L}$ PBS was used to resuspend the cell pellet, which was analyzed with the CytoFLEX LX system (Beckman Coulter, USA). FlowJo software (Leonard Herzenberg Laboratory, USA) was used to analyze flow cytometry data.

\section{Multilineage differentiation of BMSCs}

Mouse BMSCs in passage 3 were cultured in differentiation conditions to identify their capacity for multilineage differentiation. To induce adipogenic differentiation of BMSCs, when the cells reached 70 to $80 \%$ confluency, the complete medium was replaced with adipogenic induction medium (DMEM supplemented with $10 \% \mathrm{FBS}, 10^{-7} \mathrm{M}$ dexamethasone (D1756, Sigma Aldrich, Germany), $10 \mathrm{mM} \beta$-glycerol phosphate (G9422, Sigma Aldrich, Germany), $50 \mu \mathrm{M}$ Lascorbic acid 2-phosphate (49752, Sigma Aldrich, Germany), and $10 \mu \mathrm{g} / \mathrm{mL}$ insulin (I0320000, Sigma Aldrich, Germany)), and the cells were cultured for 3 weeks. Then, Oil Red O staining was performed.

To induce osteoblastic differentiation of BMSCs, when the cells reached 60 to $70 \%$ confluency, the complete medium was replaced with osteogenic induction medium (DMEM medium (SH300022.01, HyClone, USA) supplemented with $10 \%$ FBS, $10 \mathrm{mM} \beta$-glycerol phosphate
(G9422, Sigma Aldrich, Germany), $50 \mu \mathrm{M}$ L-ascorbic acid 2-phosphate (49752, Sigma Aldrich, Germany), $100 \mathrm{ng} /$ $\mathrm{mL}$ recombinant human bone morphogenic protein-2 (120-02, Peprotech, USA), and $10^{-7} \mathrm{M}$ dexamethasone (D1756, Sigma Aldrich, Germany)), and the cells were maintained in this medium for the next 21 days. Then, alizarin red staining was performed.

To induce chondrogenic differentiation of BMSCs, when the cells reached $70 \%$ confluency, the complete medium was replaced with chondrogenic induction medium (DMEM supplemented with 10\% FBS, $50 \mu \mathrm{g} / \mathrm{mL}$ L-ascorbic acid 2-phosphate (49752, Sigma Aldrich, Germany), $100 \mu \mathrm{g} / \mathrm{mL}$ sodium pyruvate (P5280, Sigma Aldrich, Germany), $40 \mu \mathrm{g} / \mathrm{mL}$ proline (P3350000, Sigma Aldrich, Germany), $10 \mathrm{ng} / \mathrm{mL}$ TGF- $\beta 1$ (100-21, Peprotech, USA), $10^{-7} \mathrm{M}$ dexamethasone (D1756, Sigma Aldrich, Germany), and $100 \mathrm{ng} / \mathrm{mL}$ insulin-like growth factor-1 (IGF-1, 100-11, Peprotech, USA)), and the cells were cultured for 3 weeks. Then, toluidine blue staining was performed.

\section{Isolation and identification of BMSC-derived EVs}

The mouse BMSCs in passage 3 were cultured in $\alpha$ MEM (SH30265.01, HyClone, USA) supplemented with EV-depleted FBS and $100 \mathrm{U} / \mathrm{mL}$ penicillin-streptomycin solution (10378016, Thermo Fisher Scientific, USA). EVdepleted FBS was depleted of EVs by ultracentrifugation for $14 \mathrm{~h}$ at $150,000 \mathrm{~g}$. Then, the supernatant was separated and used as EV-depleted FBS. The BMSC culture medium was collected every $48 \mathrm{~h}$. The collected culture medium was centrifuged at $300 \mathrm{~g}$ for $10 \mathrm{~min}$ at $4{ }^{\circ} \mathrm{C}$ to eliminate cell pellets. The supernatant was centrifuged at $2000 \mathrm{~g}$ for $20 \mathrm{~min}$ at $4{ }^{\circ} \mathrm{C}$ to further remove cell debris. Then, the supernatant was again centrifuged at $10,000 \mathrm{~g}$ for $30 \mathrm{~min}$ at $4{ }^{\circ} \mathrm{C}$. The supernatant was then filtered through a $0.22-\mu \mathrm{m}$ filter (GSWP04700, Merck, Germany), and the flow through was transferred to new tubes and ultracentrifuged at $150,000 \mathrm{~g}$ for $2 \mathrm{~h}$ at $4{ }^{\circ} \mathrm{C}$ in a SW70Ti rotor (Beckman Coulter, USA) to pellet the EVs. The supernatant was immediately aspirated upon completion of the first ultracentrifugation and then ultracentrifuged again as described previously. For maximal EV retrieval, the EV-enriched pellet was resuspended in $200 \mu \mathrm{L}$ cold PBS. The concentration of EVs was measured according to the protein content using a BCA protein assay kit (23227, Thermo Fisher Scientific, USA). The presence of EVs was confirmed with a NanoSight NS300 instrument (Malvern Instruments, UK). Transmission electron microscopy (TEM; Tecnai 12, FEI, USA) and western blot were employed to detect morphology and surface markers.

\section{Establishment and treatment of the SSc model}

BLM (R25001, Thermo Fisher Scientific, USA) was diluted in PBS at a concentration of $1 \mathrm{mg} / \mathrm{mL}$ and 
sterilized by filtration. To establish the murine fibrosis model, $100 \mu \mathrm{L}$ BLM solution was subcutaneously injected into the shaved backs $\left(1 \mathrm{~cm}^{2}\right)$ of mice using a 27 -gauge needle. Injections were made once a day for 28 consecutive days. Mice in the control group received $100 \mu \mathrm{L}$ PBS.

For the BMSC or BMSC-EV treatments, BLM-induced SSc mice were randomly divided into 3 groups (6 mice in each group) and treated with PBS $(100 \mu \mathrm{L})$, BMSCs (1 $\left.\times 10^{6} / 100 \mu \mathrm{L}\right)$, or BMSC-derived EVs $(15 \mu \mathrm{g} / 100 \mu \mathrm{L})$. The numbers of BMSCs used in this study were determined according to our previous report [10]. BMSC-EVs $(15 \mu \mathrm{g})$ were produced from $2 \times 10^{6}$ BMSCs to ensure a treatment effect. The mice were killed 14 days after treatment, and skin tissue samples were collected from a $1 \mathrm{~cm}^{2}$ shaved area.

\section{Fibroblast cell culture and treatment}

Mouse fibroblast cells were isolated from mouse skin with $0.25 \%$ trypsin and cultured in DMEM/F12 (D8437, Sigma Aldrich, Germany) with 10\% FBS (10091148, Thermo Fisher Scientific, USA). Fibroblasts were passaged and treated with $10 \mathrm{ng} / \mathrm{mL}$ TGF- $\beta 1$ or a combination of TGF- $\beta 1(10 \mathrm{ng} / \mathrm{mL})$ and BMSC-EVs $(50 \mu \mathrm{g} / \mathrm{ml})$. After that, the cells were lysed with RIPA buffer (P0013B, Beyotime, China) containing protease and phosphatase inhibitor cocktails (C0001 and C0004, TargetMol, USA) and collected for western blot analysis.

\section{Histochemical analysis}

Skin tissue samples from different groups were fixed in 4\% paraformaldehyde (PFA; E672002-0500, Sangon Biotech, China) solution for $24 \mathrm{~h}$. Then, the tissues were embedded in paraffin and cut into $10-\mu \mathrm{m}$ sections. The sections of the paraffin-embedded skin tissue were deparaffinized using xylene and rehydrated using decreasing concentrations of ethanol (100, 95, 85, and $75 \%)$. Briefly, the sections were stained in hematoxylin for $5 \mathrm{~min}$ and further washed with cold running water. After incubation with 1\% hydrochloric acid-alcohol, the sections were washed and stained with $0.5 \%$ eosin dye solution. To analyze the extent of skin fibrosis, randomly selected fields of the sections were captured. The sections were stained with Masson trichrome staining (BPDL023, SenBeijia Biological Technology Co., Ltd, China) according to the manufacturer's instructions, and the collagen fibers were evaluated under a light microscope. For detection of mast cells, the sections were stained with toluidine blue. Sections were examined and photographed using a microscope (TI2-E, Nikon, Japan).

For the inflammatory cell counts, the hematoxylinstained skin sections were examined with a light microscope at $\times 200$ magnification. We selected 3 views of each stained skin section randomly and quantified the positive stained cells by carefully counting in $0.5 \mathrm{~mm}$ broad, band-like area below and parallel with the dermal-epidermal junction.

\section{Immunohistochemical analysis}

The sections of paraffin-embedded skin tissue were deparaffinized as previously described [24]. The sections were incubated in $3 \% \quad \mathrm{H}_{2} \mathrm{O}_{2}$ for $5 \mathrm{~min}$ at room temperature. Then, 5\% goat serum (E510009, Sangon Biotech, China) was used to block the sections for 60 min at room temperature. The primary antibodies listed in Supplemental Table 1 were diluted in $5 \%$ goat serum solution, added to the sections, and incubated overnight at $4{ }^{\circ} \mathrm{C}$. Horseradish peroxidase (HRP)-labeled secondary antibodies were added and incubated for $60 \mathrm{~min}$ at room temperature. Diaminobenzidine (DAB) solution was utilized to show positive signaling.

\section{Hydroxyproline measurement}

The collagen content of skin samples was quantified with a hydroxyproline test kit (A030-2-1, Nanjing JianCheng Bioengineering Institute, China) according to the recommendations of the manufacturer. Hydroxyproline content was determined with the following formula: (tested OD value - blank OD value) / (standard OD value - blank OD value) $\times$ standard sample concentration $(5 \mu \mathrm{g} / \mathrm{mL}) \times$ total hydrolysate volume $(10 \mathrm{~mL}) /$ tissue wet weight $(\mathrm{mg})$.

\section{Western blotting analysis}

Samples were lysed with RIPA buffer (P0013B, Beyotime, China) supplemented with protease and phosphatase inhibitor cocktails (C0001 and C0004, TargetMol, USA). Total protein $(20 \mu \mathrm{g})$ was separated by SDS-PAGE (10\%) and transferred to PVDF membranes (IPFL85R, Merck, Germany). After being blocked in 5\% nonfat milk for 1 $\mathrm{h}$, the membranes were incubated with primary antibodies (as listed in Supplemental Table 1) at $4{ }^{\circ} \mathrm{C}$ overnight. After being washed, the membranes were incubated with HRP-conjugated secondary antibodies for $1 \mathrm{~h}$ at room temperature. Signals were detected using a Tanon chemiluminescence image detection system (5200S, Tanon, China).

\section{Quantitative real-time PCR}

Total RNA was extracted and purified using TRIzol reagent (9109, Takara, Japan) according to the manufacturer's instructions, and cDNA was synthesized using PrimeScript RT Master Mix (RR036A, Takara, Japan) according to the manufacturer's instructions. Quantitative real-time PCR was performed using SYBR Green Realtime PCR Master Mix (FP205-03, Tiangen, China). The oligonucleotide primers (Sangon Biotech, China) that were used are listed in Supplemental Table 2. Gene 
expression was normalized to the average value of GAPDH, $\beta$-ACTIN, and $18 \mathrm{~S}$ mRNA in each sample. The fold change in expression was calculated using the $2^{\Delta \Delta C t}$ method.

\section{RNA sequencing (RNA-seq) and bioinformatic analysis} For miRNA sequencing (miRNA-seq) of EVs, preparation of tagged miRNA-seq libraries, sequencing, and next-generation sequencing (NGS) data analysis were performed by LC Sciences (USA). The library was sequenced with the Illumina Hiseq 2500 SE50 platform. Raw reads were subjected to an in-house program, ACGT101-miR (LC Sciences, USA), to remove adapter dimers, junk, low-complexity, and common RNA families (ribosomal RNAs, transfer RNAs, small nuclear RNAs, and small nucleolar RNAs) and repeats. Subsequently, unique sequences with lengths of 18 26 nucleotides were mapped to specific species precursors in miRBase 22.0 via a BLAST search to identify known miRNAs and novel 3p- and 5p-derived miRNAs. A criterion that the number of reads was higher than the average copy number of the dataset was used to filter the high-level miRNAs. The $\mathrm{R}$ package multiMiR (version 3.12) was used for miRNA target scanning and prediction [25], while clustering analysis of the target genes was performed using the R package clusterProfiler.

For RNA-seq of tissue samples, skin tissue was dissected under a microscope and immediately placed in TRIzol reagent. Total RNA was isolated with TRIzol reagent (9109, Takara, Japan). The library was sequenced with an Illumina NovaSeq 6000 PE150. The criteria $|\log \mathrm{FC}|>1$ and $\mathrm{P}<0.05$ were applied to filter the differentially expressed genes. Gene ontology (GO) and Kyoto Encyclopedia of Genes and Genomes (KEGG) analyses were performed with the $\mathrm{R}$ package clusterProfiler. The results were visualized with GOplot.

\section{Statistical analysis}

All data are expressed as the standard error of the mean. Data analysis was performed using GraphPad Prism software (USA). One-way ANOVA was employed for the statistical comparison. A value of $P<0.05$ was considered statistically significant. In the figures, asterisks are used to express the statistical significance of values: ": $P$ $<0.05, *: P<0.01$ and ${ }^{* * *}: P<0.001$. In the results, detailed $P$ values are provided unless $P<0.001$.

\section{Results}

\section{Identification of mouse BMSCs and BMSC-derived EVs}

Following isolation and culture as described above, mouse BMSCs were identified according to the criteria of the International Society of Cellular Therapy [26]. As shown in Fig. 1a, the isolated mouse BMSCs adhered to the culture dish with fibroblast-like and spindle-shaped morphology. After adipogenic induction, small cytoplasmic lipid droplets in BMSCs were observed upon Oil Red O staining (Fig. 1b). After osteoblast induction, positive alizarin red staining could be seen (Fig. 1c). After chondrogenic induction, toluidine blue staining was observed (Fig. 1d). The surface markers of the BMSCs were analyzed with flow cytometry, and the results are shown in Fig. 1e. BMSCs highly expressed CD73 (100\%), CD105 (100\%), CD44 (97\%), and CD90 (95\%), while CD31 and CD45 were negatively expressed. Thus, the mouse BMSCs exhibited typical mesenchymal stem cell characteristics.

The EVs isolated from the mouse BMSC culture media were analyzed with a NanoSight NS300 particle size analyzer. As shown in Fig. 1f, most of these EVs ranged from 90 to $230 \mathrm{~nm}$ in size, and they appeared as round or elliptical vesicles of uneven size with intact capsules under TEM (Fig. 1g). Moreover, the EV-specific markers CD9, CD63, and ALIX were significantly enriched in these EVs. CALNEXIN and GAPDH were not expressed by the EVs (Fig. 1h). Taken together, these data show that mouse BMSCs and BMSC-derived EVs were isolated successfully.

\section{Administration of BMSCs or BMSC-EVs reduces BLM- induced dermal thickening and fibrosis}

To confirm the effects of BMSCs in SSc that we previously reported and examine whether mouse BMSC-EVs have any effects on BLM-induced SSc pathology, a mouse model was established according to the following protocol: daily subcutaneous injection of BLM for 4 weeks, followed by subcutaneous injections of mouse BMSCs or BMSC-EVs (Fig. 2a). BLM, BMSCs, and BMSC-EVs were subcutaneously injected into the centers of shaved skin areas for even distribution of the liquid and effects (Fig. 2b).

Two weeks after the BMSC and EV treatments, in comparison with the respective layers of normal mouse skin, the dermis layer of PBS-treated model mice was thickened $(P<0.001)$, the subcutaneous adipose layer of PBS-treated model mice was lost, and the dermal architecture of PBS-treated model mice was disrupted (Fig. 2c, d). Both the BMSC- and EVtreated skin samples showed normal thickness of the subcutaneous adipose layer, and in both cases, the hypodermic adipose layer was significantly thicker than that in the PBS-treated mice $(P<0.001)$ (Fig. 2c, e). Furthermore, when inflammatory cell infiltration was examined as another parameter to evaluate the effects of the treatments in SSc, as shown in Fig. 2f, the inflammatory cell counts in skin tissue sections in both the BMSC and EV groups were significantly lower than those in SSc mice $(P<0.001)$, indicating attenuated leucocytic infiltration. These results 


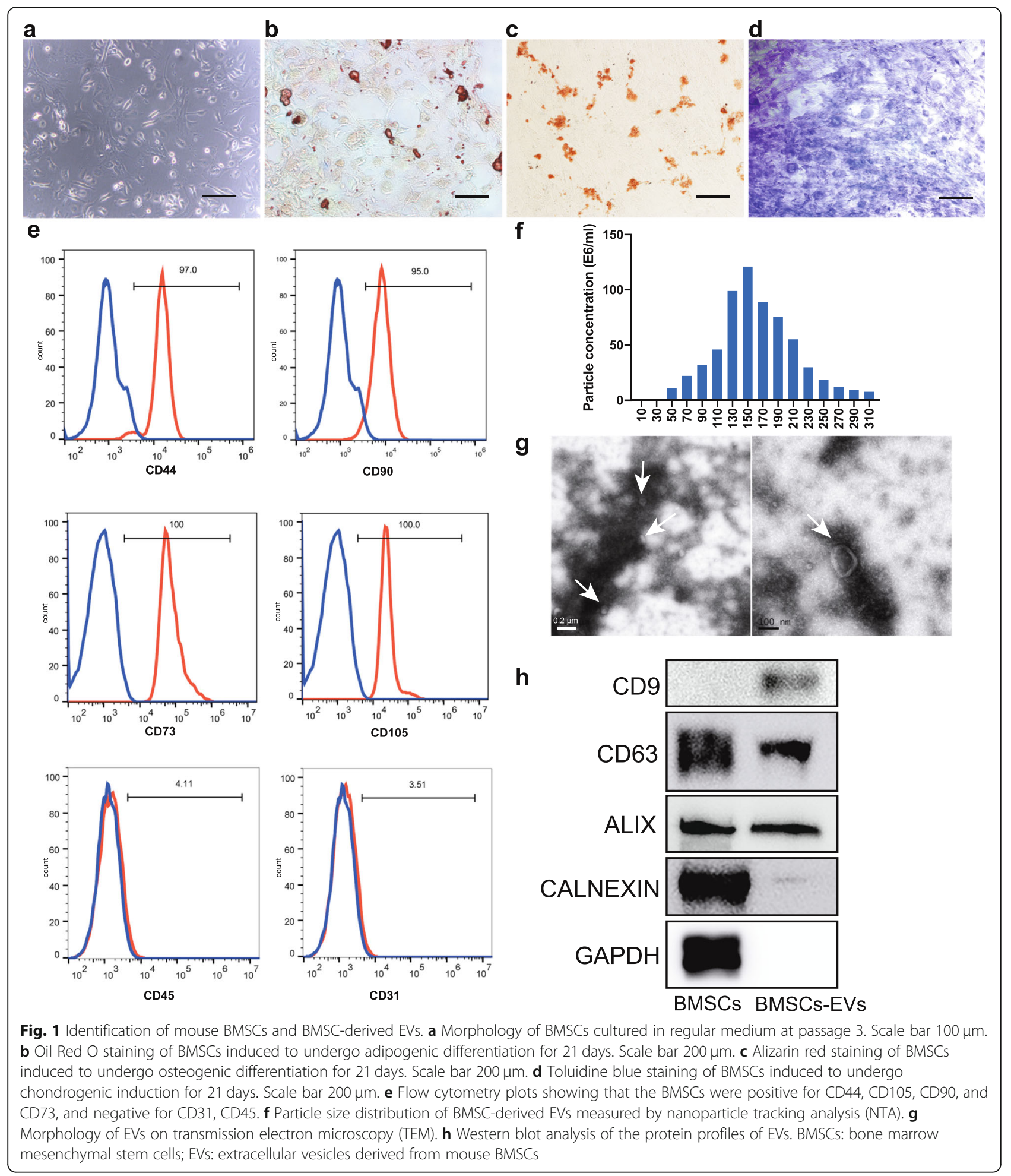

demonstrate that subcutaneously injected BMSC-EVs can significantly improve dermal damage and abnormalities in this SSc model, and their effects were as strong as those of mouse BMSCs.
Administration of BMSCs and BMSC-EVs reduces abnormal deposition of collagen in a mouse SSc model Considering that abnormal ECM deposition in the dermis is an atypical characteristic of SSc, Masson's 


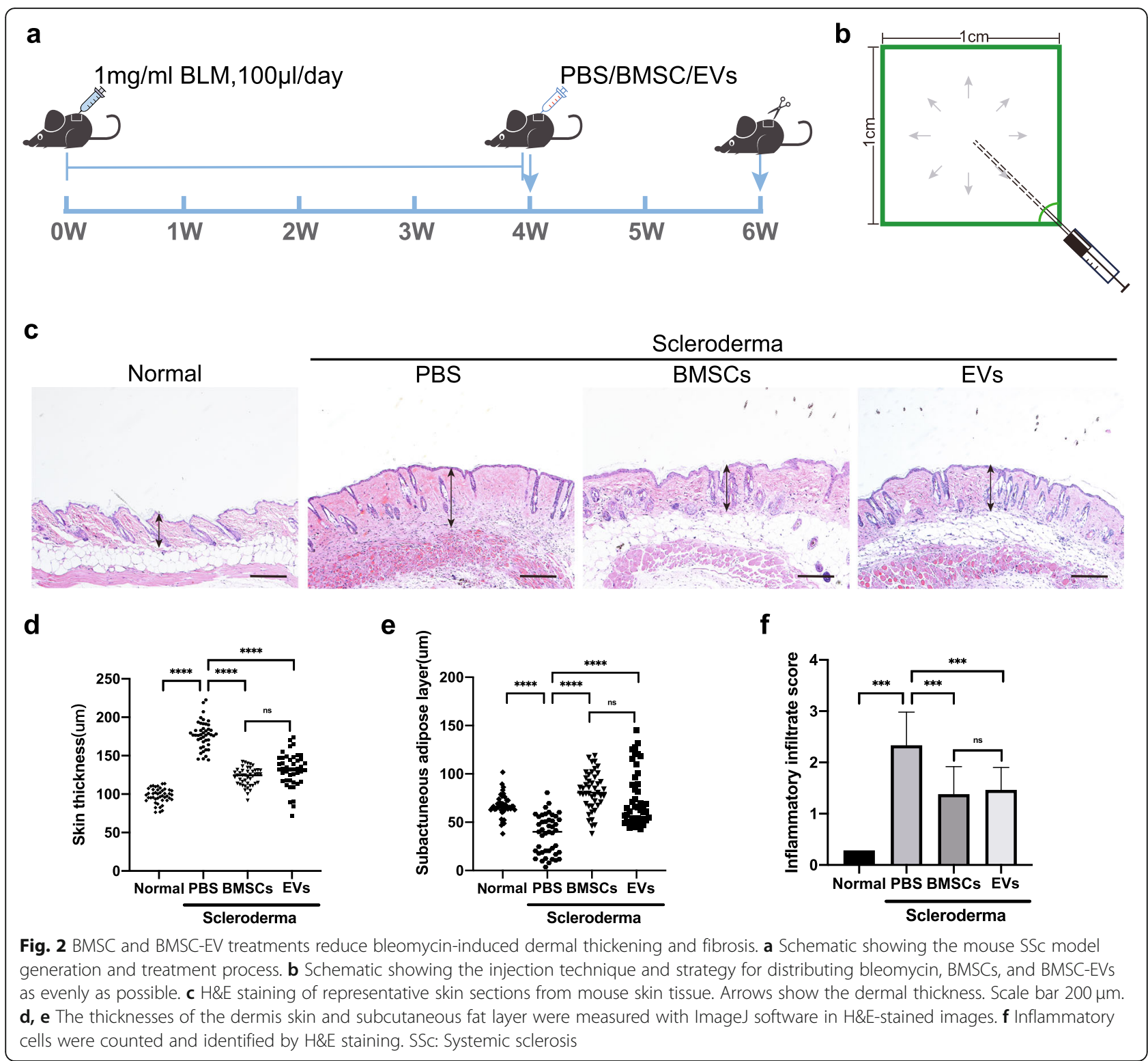

trichrome staining was used to evaluate the ability of BMSCs and BMSC-EVs to ameliorate the deposition of excess ECM components, including collagen. As shown in Fig. 3a, BLM-induced scleroderma skin exhibited an abundance of collagen and a dense ECM structure in the dermis, but ECM deposition was significantly reduced by treatment with BMSCs or BMSC-EVs. Consistently, as shown in Fig. $3 \mathrm{~b}$, the BMSC $(P<0.001)$ and BMSC$\mathrm{EV}(P<0.001)$ treatments significantly decreased the hydroxyproline content, which was increased in the BLMtreated mice, and there was no significant difference between the BMSC group and BMSC-EV group $(P=$ 0.499). Furthermore, the mRNA expression levels of Col1 and Fn1 were significantly elevated in PBS-treated
SSc mice $(P<0.001)$ but were significantly reduced in mice treated with either BMSCs $(P<0.001)$ or BMSCEVs $(P=0.0027)($ Fig. $3 \mathrm{c}, \mathrm{d})$. The protein expression results for COL1 and FN1 were consistent with the mRNA expression results (Fig. 3e, f). However, for these two markers, the effects of BMSC-EVs were not as strong as those of BMSCs (Fig. 3c-f). These data indicate that both BMSCs and BMSC-EVs can significantly reduce BLM-induced abnormal deposition of ECM and collagen density.

\section{Analysis of BMSC-EVs and their specific miRNAs}

Since both mouse BMSCs and their EVs attenuated the generation of disordered dermis structure and ECM 


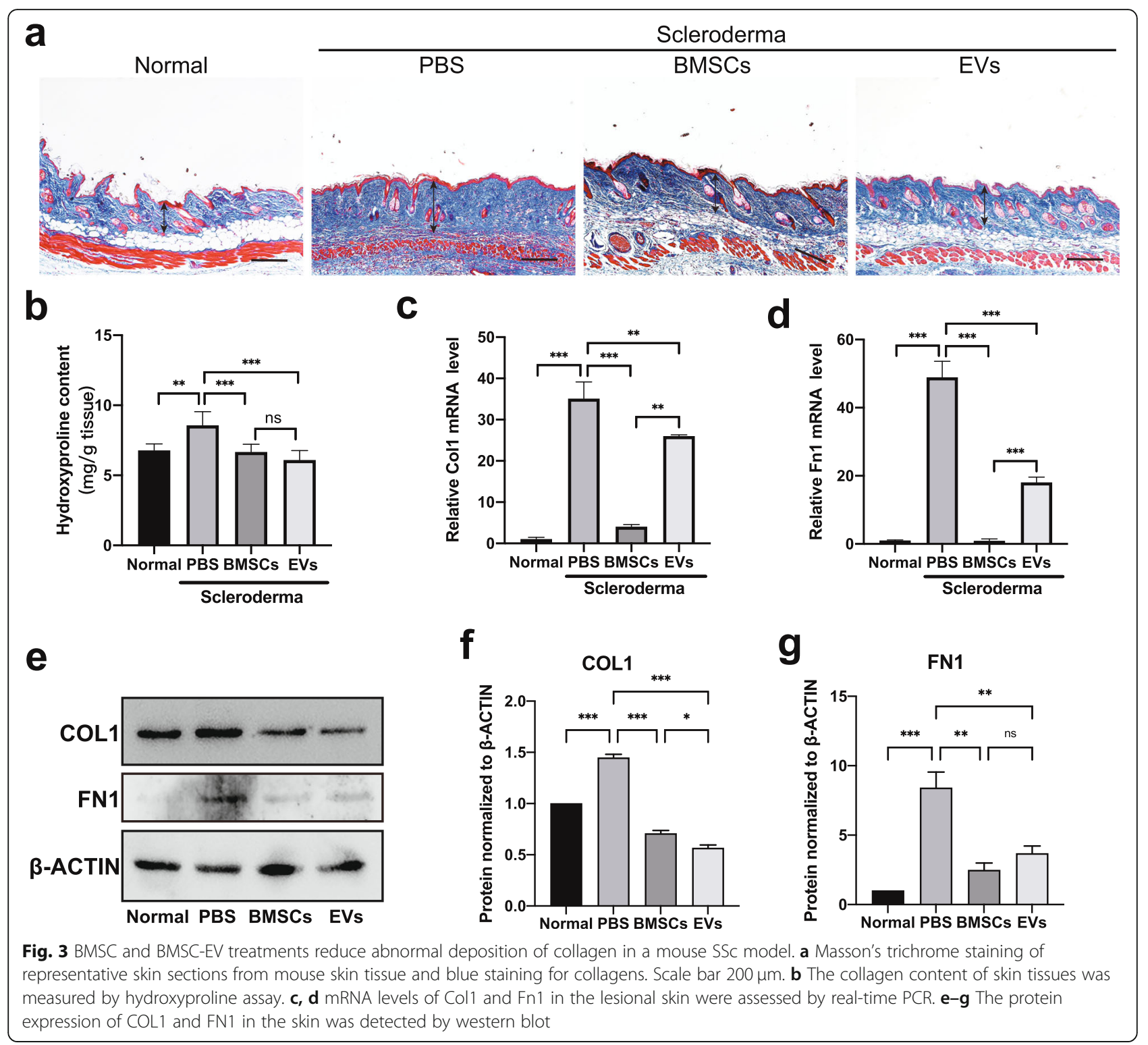

deposition in the skin of BLM-induced SSc mice to a similar degree, we focused on BMSC-EVs and their functional miRNAs in the experiments below to understand the related mechanism and develop more convenient and efficient therapy. First, the global expression of miRNAs in BMSC-EVs was analyzed via highthroughput miRNA-seq approaches. As listed in Supplemental Table 3, BMSC-EVs highly expressed a cluster of specific miRNAs, such as mir-21a, mir-143, mir-27b, mir-29a, and let-7. The target genes of these highly expressed miRNAs were then studied by miRNA target scan analysis and GO functional clustering analysis to predict their potential functions. As shown in Fig. 4a, the results showed that these highly expressed miRNAs were involved in regulating the proliferation and differentiation of multiple cell types, including muscle cells, $\mathrm{T}$ cells, and fat cells, and in multiple processes, such as ECM generation (including processes related to collagen and cell adhesion and junctions). In addition, the WNT, TGF $\beta$, Notch, and T cell receptor signaling pathways were also predicted to play certain roles in regulating the homeostasis of skin (Fig. 4b-d).

To confirm the functional predictions for the BMSCEV-derived miRNAs in vivo, high-throughput RNA-seq was performed to analyze the skin tissues of BLMtreated mice with or without 7 days of BMSC-EV treatment. As shown in Supplemental Fig. 1a, in comparison with that of normal control mice, the skin of the SSc mice highly expressed genes involved in the hedgehog signaling pathway, the WNT pathway, the cell cycle and 

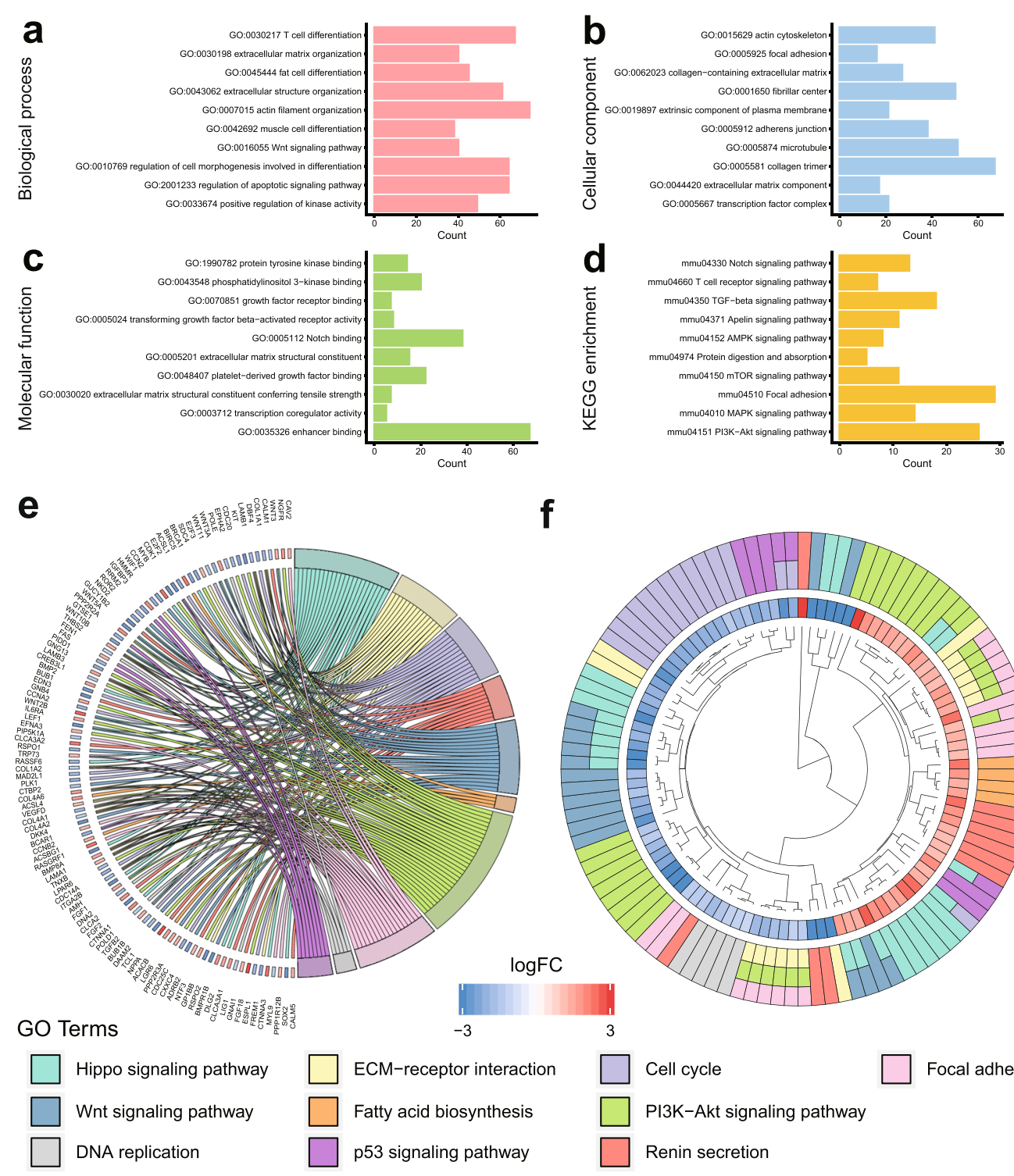

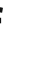

g
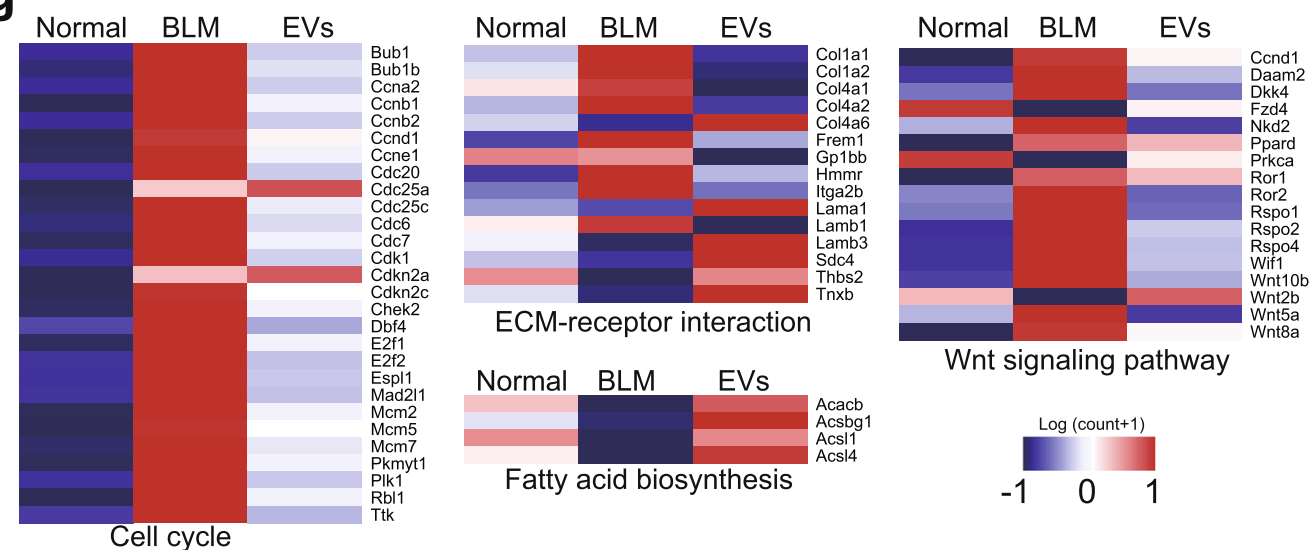

Wnt signaling pathway

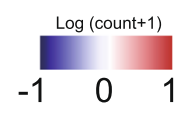

Fig. 4 (See legend on next page.) 
(See figure on previous page.)

Fig. 4 High-throughput sequencing analysis of miRNAs in BMSC-EVs and the transcriptome of skin tissues. a-d Gene Ontology analysis of the genes targeted by the highly expressed microRNAs in BMSC-EVs. e,f Gene Ontology and GO Chord analysis results showing the differentially expressed genes between BMSC-EV-treated skin and PBS-treated skin. $\mathbf{g}$ Heatmap showing the relative mRNA expression of members of related signaling pathways

cellular senescence signaling, but the skin of BMSC-EVtreated SSc mice highly expressed genes related to focal adhesion, the Hippo signaling pathway, and fatty acid biosynthesis. Reasonably, following BMSC-EV treatment, the genes that were hyperactivated by BLM stimulation were significantly lowered, especially those in the WNT pathway, or related to ECM-receptor interactions and the cell cycle (Fig. 4e, g); however, genes related to fatty acid synthesis were upregulated. There were only a few genes that were differentially expressed between the BMSC-EV-treated group and the normal control group (Supplemental Fig. 1b).

These results suggest that the BMSC-EVs may function by regulating the WNT signaling pathway, TGF $\beta$ signaling, and inflammatory response during the treatment of BLM-induced SSc.

\section{BMSC-EV treatment decreases fibroblast differentiation into myofibroblasts}

Considering the important roles of the TGF $\beta$ signaling pathway in inducing fibroblast activation and myofibroblast differentiation, both are important characteristics during the progression of BLM-induced animal models of fibrosis. As such, TGF- $\beta 1$-positive cells and TGF- $\beta 1$ mRNA expression were examined in the skin samples of the mice. As shown in Fig. 5a, c, there was significantly more accumulation of TGF- $\beta 1$-positive cells in the dermis layer in the SSc mice than in the normal mice $(P<$ $0.001)$, but this accumulation was evidently reduced in the EV-treated group to a level similar to that in the normal group $(P<0.001)$. The mRNA and protein levels of the groups showed similar trends $(P<0.001)$ (Fig. 5d, g).

Another typical characteristic of SSc, increased $\alpha$ SMA-positive myofibroblasts in fibrotic skin [27, 28], was also examined in the same model. As shown in Fig. $5 \mathrm{~b}, \mathrm{e}, \mathrm{g}, \mathrm{i}$, the number of $\alpha-\mathrm{SMA}^{+}$myofibroblasts was evidently increased in the scleroderma skin of BLMtreated mice $(P<0.001)$ but was reduced to normal levels in the EV-treated mice $(P<0.001)$. Consistently, the mRNA and protein levels of $\alpha$-SMA in the SSc model were significantly higher than those in control mice $(P<0.001)$ and were reduced to normal levels after BMSC-EV treatment $(P<0.001)$ (Fig. 5f, g, h). These results confirm that BMSC-EVs can inhibit fibroblast activation by downregulating the expression of TGF- $\beta 1$ in the dermis.

\section{BMSC-EV treatment reduces inflammatory infiltration in the dermis in scleroderma}

To support our ideas above, more parameters related to SSc, like degranulation of mast cells and accumulation of macrophages and lymphocytes, were examined [29]. As shown in Fig. 6a, b, the number of mast cells in the dermis of the BLM-treated mice was significantly increased, as shown by toluidine blue staining, compared to that in normal control mice $(P<0.001)$, and BMSCEV treatment significantly reduced the mast cell number to a level comparable to that of the normal group $(P<$ 0.001). Moreover, as shown in Fig. 6c-h, immunohistochemical examination demonstrated that BMSC-EVs significantly reduced the infiltration of $\mathrm{F} 4 / 80^{+}$macrophages $(P<0.001)$ and $\mathrm{CD} 4^{+} / \mathrm{CD} 8^{+}$lymphocytes $(P<$ $0.001)$, and both were significantly increased in BLMtreated SSc mice.

To investigate the effects of BMSC-EVs on BLMinduced inflammation, the mRNA expression of inflammatory cytokines, including Il-10, Il- 6 , and Tnf- $\alpha$, in skin samples was detected. The results showed that BLMtreated mice had significantly higher mRNA levels of Il$6(P<0.001)$, Il-10 $(P=0.0056)$, and Tnf- $\alpha(P=0.0024)$ than normal control mice, while the levels of Il-6 $(P<$ $0.001)$ and Il-10 $(P=0.0067)$ in the EV-treated group are significantly reduced (Fig. 6i, j). The levels of Tnf- $\alpha$ in the EV-treated group were not significantly different (Fig. 6k). The protein expression patterns for IL6, IL10, and TNF- $\alpha$ were the same as the mRNA expression patterns: the expression of IL6 and IL10 was higher in BLM-treated mice, while it was significantly reduced in the EV-treated group (Fig. 6l-o). Thus, BMSC-EV treatment can significantly reduce the infiltration of inflammatory cells and inhibit the release of inflammatory factors in the skin of BLM-induced SSc mice.

\section{Discussion}

Curing scleroderma (SSc) is now a realistic clinical challenge $[3,4]$ since its etiology and pathogenesis are unclear. The key clues about its possible mechanisms are limited to vasculopathy, immune dysfunction, and fibroblast dysfunction [1, 2]. On the other hand, BMSCbased therapies, including that used in our previous work [10], have shown some therapeutic effects, like attenuating skin fibrosis and apoptosis in the BLMinduced SSc model. The observation that interested us was that the colony-forming unit number and 


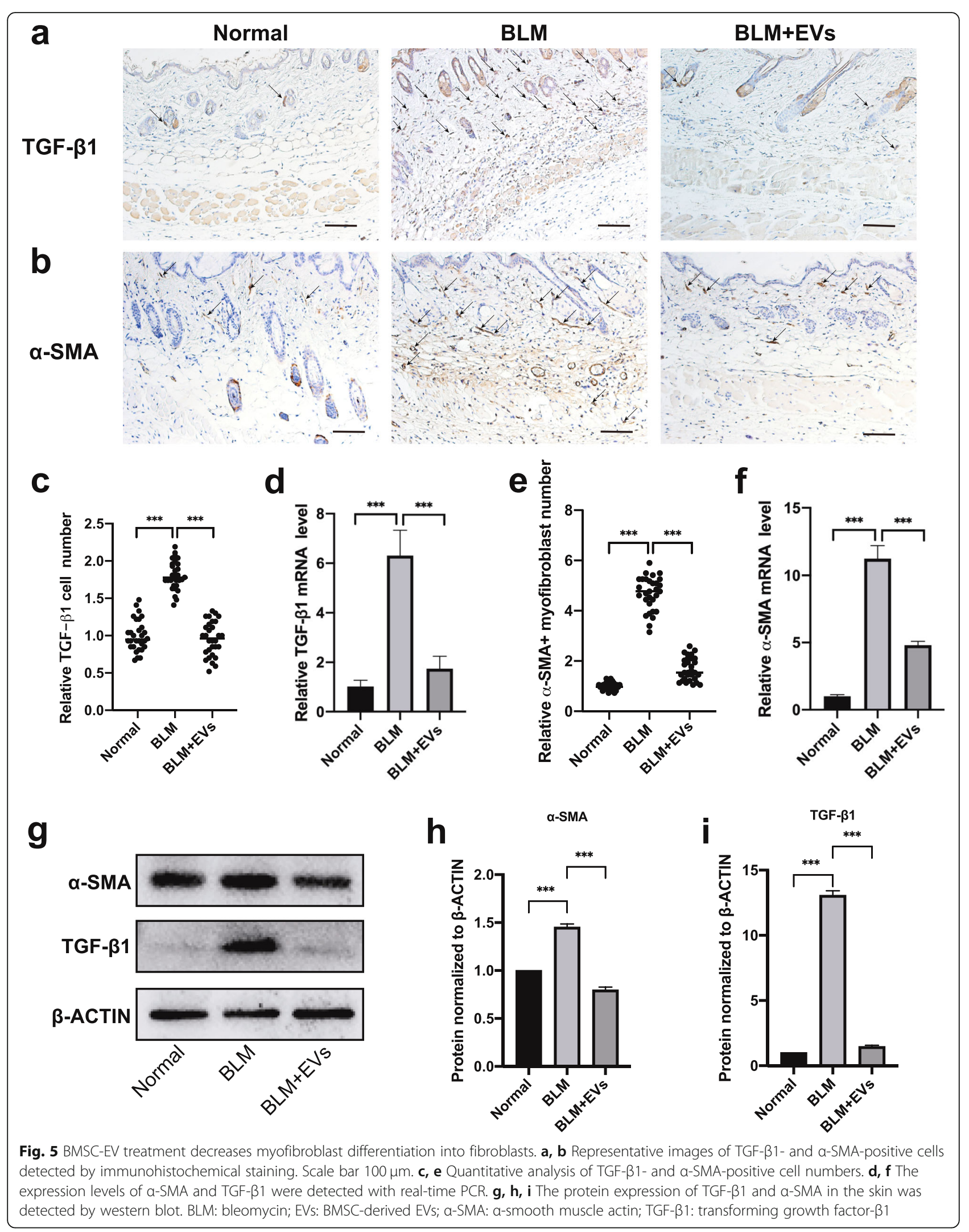




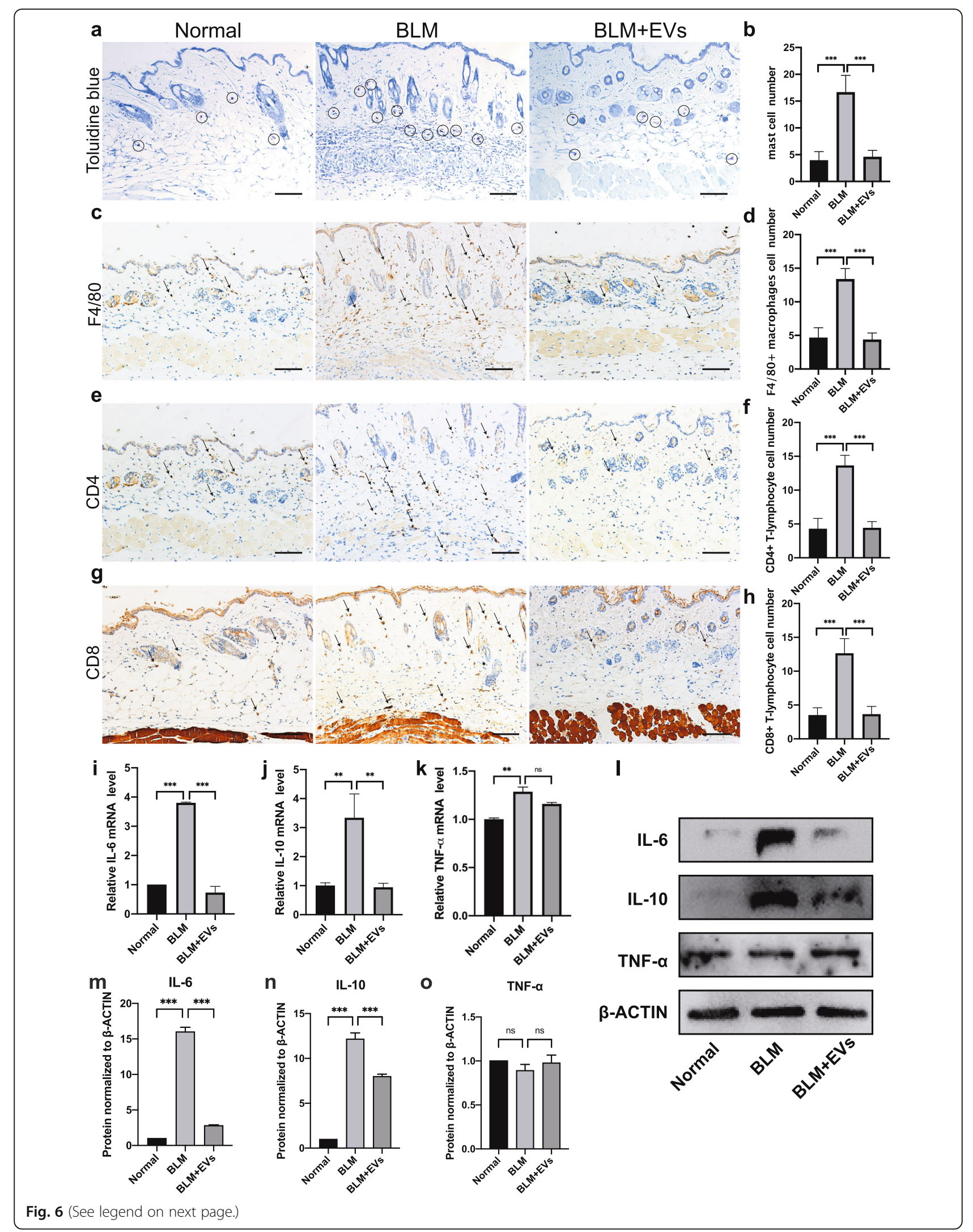


(See figure on previous page.)

Fig. 6 BMSC-EV treatment reduces inflammatory infiltration in the dermis in scleroderma. a-h Representative images of the mast cell degranulation detected by toluidine blue staining $(\mathbf{a}, \mathbf{b}), \mathrm{F} 4 / 80^{+}$positive macrophages $(\mathbf{c}, \mathbf{d}), C D 8^{+}$and $C D 4^{+}$positive lymphocyte $(\mathbf{e}, \mathbf{f}, \mathbf{g}, \mathbf{h})$ infiltration in the skin detected by immunostaining and their corresponding quantification. Scale bar $100 \mu \mathrm{m}$. i-k Quantification of $\|6\|$,10 , and Tnf-a mRNA. I-o Protein expression of IL-6, IL-10, and TNF-a in the skin as detected by western blot. EVs: BMSC-derived EVs; BLM: bleomycin; Il6: interleukin-6; II10: interleukin-10; Tnf-a: tumor necrosis factor a

differentiation efficiency of the BMSCs were fewer or lower in the injected sites [12]. This result may indicate that the therapeutic mechanism of these BMSCs in treating SSc involves paracrine signaling rather than differentiation. Therefore, in this study, we used BMSCs as a tool to explore the pathogenesis of scleroderma and to develop a more practical treatment by exploring BMSCEVs and their components. Again, BLM-induced SSc mice were used as models of the disease since the pathological changes in the mice, like increased dermal thickness and collagen accumulation, are similar to those in patients with SSc [29].

MSCs have been reported to play an antifibrotic role in fibrotic diseases such as liver fibrosis [30], kidney fibrosis [31], lung fibrosis [32, 33], and skin fibrosis [10]. However, there are still unresolved and unavoidable risks of MSC clinical applications, such as iatrogenic tumor formation, cellular rejection, and infusion toxicity [34]. Additionally, the use of cells as drugs is still in a very preliminary stage, and the evaluation and approval of such drugs for clinical use are a long way off. On the other hand, EVs derived from MSCs have been shown to be key factors in MSC-to-surrounding cell communication [35] and are considered stem cell-based, cell-free drugs and carriers of siRNA [36]. Compared to BMSCs, BMSC-EVs have several advantages, like being simpler to produce and store and having easier quality control procedures. As EVs are not cells, viability is not a concern. This makes EVs potentially much easier to use than cells post thaw. Indeed, there is preliminary evidence that the thawing process may alter membranes of EVs so that they are more easily absorbed by target cells [37]. The safety of intravenous and intraperitoneal injection of EVs has been verified in animal experiments [38, 39]. However, the large-scale production of EVs is influenced by the specific therapeutic application. As products of cells, the manufacture of EVs is dependent on the ability to produce large quantities of cells in ways that do not alter certain cell behavior and characteristics. Some alterations in the cell culture platform might alter the production, composition, attributes, or function of EVs [40]. Furthermore, some primary cell lines (such as mesenchymal stem cells) exhibit a low proliferative capacity, limiting the ultimate culture size and duration, number of production batches, and reproducibility. Solutions to these issues include cell immortalization via overexpression of the MYC gene [41]. Furthermore, the safety and efficiency of MSC-derived EVs have been evaluated in several clinical trials for various diseases, including an inhaled form in severe acute respiratory syndrome coronavirus 2 (NCT04276987, ChiCTR2000030261) and an intravenous injection in diabetes mellitus (NCT02138331). Therefore, we designed the present study to determine whether BMSC-EVs can mediate the effects of BMSCs in treating SSc with the hope that they can be developed into a therapy that lacks the risks of MSCs. As expected, subcutaneous BMSC-EV treatment significantly improved BLM-induced dermal damage and abnormalities and reduced ECM deposition and collagen density. The therapeutic effects of the BMSC-EVs were as strong as those of the BMSCs. Therefore, BMSC-EVs have great potential to be developed as a new therapy for SSc.

EVs serve as carriers that transport functional proteins, mRNAs, and miRNAs to various cells, where these factors act as mediators of intercellular communication and signaling pathways $[42,43]$. Studies have proven that MSC-EV miRNAs possess the abilities to promote cell proliferation, accelerate injured tissue repair, and inhibit fibrotic diseases [16, 44-46]. In this study, we further demonstrated that there are a series of miRNAs in BMSC-EVs that contribute to the alleviation of SSc by regulating relevant signaling pathways. Previously, the TGF $\beta$ pathway, Toll-like receptor signaling, and the WNT pathway were reported to be the main dysfunctional signaling pathways in the skin of patients with SSc [47], and the TGF $\beta$ and $W n t / \beta$-catenin pathways have been found to be hyperactivated to promote ECM production and induce fibrosis [48, 49]. In this study, we focused on these signaling pathways, and our data suggest that BMSC-EVs might treat BLMinduced SSc by regulating the TGF $\beta$ and WNT pathways as well as the inflammatory response. In a fibroblast SSc model induced by TGF- $\beta 1$ modulation, the SSc markers COL1, FN1, and $\alpha$-SMA and the inflammatory factors IL- 6 and IL-10 were upregulated in the TGF- $\beta 1$-treated fibroblast, and the increase in proteins was inhibited by the BMSC-EVs (Supplemental Fig. 2a). Additionally, the WNT signaling pathway proteins $\beta$-CATENIN and LEF1 and the TGF $\beta$ signaling pathway proteins phosphorylated Smad2 and phosphorylated Smad3 were upregulated in TGF $\beta 1$ treated fibroblasts and suppressed in BMSC-EV- 
treated fibroblasts (Supplemental Fig 2b). EVs inhibited fibroblast activation by downregulating the expression of TGF- $\beta 1$ in the dermis, significantly reduced the infiltration of inflammatory cells and inhibited the release of inflammatory factors in the skin of BLM-induced SSc mice. All these effects were related to the miRNAs of the BMSC-EVs.

The miRNA let-7 family contains let-7a, 7b, 7c, 7d, 7e, 7f, $7 \mathrm{~g}, 7 \mathrm{i}$, and 7j, mir-29, mir-125, and mir-21. All these miRNAs were found to be highly expressed in mouse BMSC-EVs in this study. let-7 was the first discovered miRNA and is functionally conserved in vertebrates [50]; in addition, it was reported to inhibit the production of proinflammatory cytokines such as $\mathrm{Il} 8$ and receptors such as Il1r1 and Il23r to negatively regulate the differentiation of Th17 cells and to regulate natural killer $\mathrm{T}$ cells [51-53]. Both EVs and miRNAs can regulate the TGF $\beta$ signaling pathway. For example, the downregulation of the Let-7, mir-29, and mir-30 families in idiopathic pulmonary fibrosis is related to the TGF $\beta$ pathway [54, 55], and mir-29 knockdown significantly upregulates TGF $\beta$ signaling in the induction of pulmonary fibrosis [54]. Moreover, let-7 cooperates with miR99a and miR-125b, both of which are highly expressed in BMSC-EVs, when targeting receptor subunits and SMAD signaling transducers to block the TGF $\beta$ pathway [56]. TGF $\beta$ signaling and Wnt signaling have been found to promote each other to induce fibrosis in SSc $[57,58]$. Mir-21 and mir-29 have been reported to target transducers of Wnt signaling [59,60]. Thus, miRNAs from BMSC-EVs could regulate dysfunctional signals from pathways like the TGF $\beta$ and Wnt pathways to ameliorate SSc symptoms, including ECM deposition and inflammatory infiltration. This study increases the understanding of the molecular regulation of EV-mediated miRNAs in SSc pathogenesis and of the treatment of SSc with BMSC-EVs.

\section{Conclusion}

BMSC-derived EVs could effectively treat the dysfunction and fibrosis of skin in a murine SSc model, demonstrating their potential as a replacement for related stem cell therapies. The miRNAs of BMSC-EVs might alleviate ECM deposition and inflammatory infiltration by regulating the TGF $\beta$ and WNT signaling pathways. For the first time, BMSC-EVs were proven to be able to intervened SSc in mice, and BMSC-EVs may provide a potential cure for patients with SSc.

\section{Abbreviations}

BLM: Bleomycin; BMSC: Bone marrow mesenchymal stem cell;

ECM: Extracellular matrix; EVs: Extracellular vesicles; FBS: Fetal bovine serum; GO: Gene Ontology; HRP: Horseradish peroxidase; IL: Interleukin;

ROS: Reactive oxygen species; MSC: Mesenchymal stem cell; PBS: Phosphatebuffered saline; PFA: Paraformaldehyde; SSc: Systemic sclerosis;

TEM: Transmission electron microscopy; TGF $\beta$ : Transforming growth factor $\beta$

\section{Supplementary Information}

The online version contains supplementary material available at https://doi. org/10.1186/s13287-021-02400-y.

Additional file 1: Supplemental Fig. 1. GO analysis of the DEGS between BLM-induced SSC and control skin and between EV-treated and control skin. (a-b) GO Chord analysis results showing the Gene Ontology functions of differentially expressed genes between BLM-induced SSC skin and normal skin (a) and between BMSC-EV-treated skin and normal skin (b).

Additional file 2: Supplemental Fig. 2. BMSC-derived EVs suppress the TGF- $\beta 1$-induced myofibroblast differentiation of mouse fibroblasts. (a) Protein expression profiles of SSc-related ECM and inflammatory factors in vitro. (b) Proteins related to WNT signaling pathway and TGF $\beta$ signaling pathway activation.

Additional file 3 .

Additional file 4.

\section{Acknowledgements}

Not applicable.

\section{Authors' contributions}

JJ and QO conceived and designed the experiments, performed the experiments, analyzed the data, and drafted the paper. ZW and QO analyzed the bioinformatic data. JZ, G-TX, CJ, and LL contributed to overall supervision of the project and designing the experiments, provided financial support, participated in manuscript drafting and revision, and approved the final manuscript before submission. The others contributed reagents/materials/ analysis tools. All authors read and approved the final manuscript.

\section{Funding}

This paper was supported by the National Natural Science Foundation of China (81874240, 32070719, 81372071), the Ministry of Science and Technology of China (2020YFA0113100, 2016YFA0101300), the China Postdoctoral Science Foundation (2019 M661631, 2020 M681380), and the Shanghai Science and Technology Committee Grant (18411953400).

\section{Availability of data and materials}

RNA-seq data generated in the study can be accessed via the Gene Expression Omnibus under the accession codes GSE164965 and GSE165117. (https://www.ncbi.nlm.nih.gov/geo/query/acc.cgi?acc = GSE164965 and https://www.ncbi.nlm.nih.gov/geo/query/acc.cgi?acc = GSE165117). All other data are included within the article and its additional files.

\section{Declarations}

Ethics approval and consent to participate

All animal procedures were performed according to the institutional guidelines, the Guide for the Care and Use of Laboratory Animals issued by the $\mathrm{NIH}$, and the guidelines of the animal experimentation ethics committee of Tongji University (approval NO. TJHBLAC-2019-019).

\section{Consent for publication}

Not applicable.

\section{Competing interests}

The authors declare that they have no competing interests.

\section{Author details}

${ }^{1}$ Department of Dermatology, Tongji Hospital, School of Medicine, Tongji University, Shanghai 200065, China. ${ }^{2}$ Department of Ophthalmology of Shanghai Tenth People's Hospital, and Laboratory of Clinical Visual Science of Tongji Eye Institute, School of Medicine, Tongji University, Shanghai 200072, China. ${ }^{3}$ Translational Medical Center for Stem Cell Therapy and Institute for Regenerative Medicine, Shanghai East Hospital, School of Life Sciences and Technology, Tongji University, Shanghai 200120, China. 


\section{Received: 10 February 2021 Accepted: 18 May 2021} Published online: 05 June 2021

\section{References}

1. Allanore $Y$, Simms R, Distler O, Trojanowska M, Pope J, Denton CP, et al. Systemic sclerosis. Nat Rev Dis Primers. 2015;1(1):15002. https://doi.org/10.1 038/nrdp.2015.2

2. Gabrielli A, Avvedimento EV, Krieg T. Scleroderma. N Engl J Med. 2009; 360(19):1989-2003. https://doi.org/10.1056/NEJMra0806188.

3. Guillevin L, Hunsche E, Denton CP, Krieg T, Schwierin B, Rosenberg D, et al. Functional impairment of systemic scleroderma patients with digital ulcerations: results from the DUO Registry. Clin Exp Rheumatol. 2013;31(2 Suppl 76):71-80

4. Mathai SC, Hummers LK, Champion HC, Wigley FM, Zaiman A, Hassoun PM, et al. Survival in pulmonary hypertension associated with the scleroderma spectrum of diseases: impact of interstitial lung disease. Arthritis Rheum. 2009;60(2):569-77. https://doi.org/10.1002/art.24267.

5. Pattanaik D, Brown M, Postlethwaite BC, Postlethwaite AE. Pathogenesis of Systemic Sclerosis. Front Immunol. 2015;6:272.

6. Varga J, Abraham D. Systemic sclerosis: a prototypic multisystem fibrotic disorder. J Clin Invest. 2007;117(3):557-67. https://doi.org/10.1172/JCI31139.

7. Higashi-Kuwata $\mathrm{N}$, Jinnin M, Makino T, Fukushima S, Inoue $Y$, Muchemwa FC, et al. Characterization of monocyte/macrophage subsets in the skin and peripheral blood derived from patients with systemic sclerosis. Arthritis Res Ther. 2010;12(4):R128. https://doi.org/10.1186/ar3066.

8. Huang J, Maier C, Zhang Y, Soare A, Dees C, Beyer C, et al. Nintedanib inhibits macrophage activation and ameliorates vascular and fibrotic manifestations in the Fra2 mouse model of systemic sclerosis. Ann Rheum Dis. 2017;76(11):1941-8. https://doi.org/10.1136/annrheumdis-2016-210823.

9. Katsumoto TR, Whitfield ML, Connolly MK. The pathogenesis of systemic sclerosis. Annu Rev Pathol. 2011;6(1):509-37. https://doi.org/10.1146/a nnurev-pathol-011110-130312.

10. Jiang M, Yu Y, Luo J, Gao Q, Zhang L, Wang Q, et al. Bone marrow-derived mesenchymal stem cells expressing thioredoxin 1 attenuate bleomycininduced skin fibrosis and oxidative stress in scleroderma. J Invest Dermatol. 2017;137(6):1223-33. https://doi.org/10.1016/j.jid.2017.01.011.

11. Williams AR, Hare JM. Mesenchymal stem cells: biology, pathophysiology, translational findings, and therapeutic implications for cardiac disease. Circ Res. 2011;109(8):923-40. https://doi.org/10.1161/CIRCRESAHA.111.243147.

12. Maria AT, Toupet $K$, Maumus M, Fonteneau G, Le Quellec A, Jorgensen C, et al. Human adipose mesenchymal stem cells as potent anti-fibrosis therapy for systemic sclerosis. J Autoimmun. 2016;70:31-9. https://doi.org/1 0.1016/j.jaut.2016.03.013.

13. Kourembanas S. Exosomes: vehicles of intercellular signaling, biomarkers, and vectors of cell therapy. Annu Rev Physiol. 2015;77(1):13-27. https://doi. org/10.1146/annurev-physiol-021014-071641.

14. Lai RC, Yeo RW, Lim SK. Mesenchymal stem cell exosomes. Semin Cell Dev Biol. 2015:40:82-8. https://doi.org/10.1016/j.semcdb.2015.03.001.

15. Phinney DG, Pittenger MF. Concise review: MSC-derived exosomes for cellfree therapy. Stem Cells. 2017;35(4):851-8. https://doi.org/10.1002/stem.2575.

16. Valadi H, Ekström K, Bossios A, Sjöstrand M, Lee JJ, Lötvall JO. Exosomemediated transfer of mRNAs and microRNAs is a novel mechanism of genetic exchange between cells. Nat Cell Biol. 2007;9(6):654-9. https://doi. org/10.1038/ncb1596.

17. Bollini S, Smits AM, Balbi C, Lazzarini E, Ameri P. Triggering endogenous cardiac repair and regeneration via extracellular vesicle-mediated communication. Front Physiol. 2018;9:1497. https://doi.org/10.3389/fphys.2 018.01497 .

18. Cunnane EM, Weinbaum JS, O'Brien FJ, Vorp DA. Future perspectives on the role of stem cells and extracellular vesicles in vascular tissue regeneration. Front Cardiovasc Med. 2018;5:86. https://doi.org/10.3389/fcvm.2018.00086.

19. Park K. Exosome-based therapeutic approach for muscle regeneration. J Control Release. 2016;222:176. https://doi.org/10.1016/j.jconrel.2016.01.003.

20. Wu P, Zhang B, Shi H, Qian H, Xu W. MSC-exosome: a novel cell-free therapy for cutaneous regeneration. Cytotherapy. 2018;20(3):291-301. https://doi.org/10.1016/j.jcyt.2017.11.002.

21. Shojaati G, Khandaker I, Funderburgh ML, Mann MM, Basu R, Stolz DB, et al. Mesenchymal stem cells reduce corneal fibrosis and inflammation via extracellular vesicle-mediated delivery of miRNA. Stem Cells Transl Med. 2019;8(11):1192-201. https://doi.org/10.1002/sctm.18-0297.
22. Wang B, Yao K, Huuskes BM, Shen HH, Zhuang J, Godson C, et al. Mesenchymal stem cells deliver exogenous MicroRNA-let7c via exosomes to attenuate renal fibrosis. Mol Ther. 2016;24(7):1290-301. https://doi.org/10.1 038/mt.2016.90

23. Zhu LP, Tian T, Wang JY, He JN, Chen T, Pan M, et al. Hypoxia-elicited mesenchymal stem cell-derived exosomes facilitates cardiac repair through miR-125b-mediated prevention of cell death in myocardial infarction. Theranostics. 2018;8(22):6163-77. https://doi.org/10.7150/thno.28021.

24. Robertson D, Isacke CM: Multiple immunofluorescence labeling of formalinfixed paraffin-embedded tissue. Methods Mol Biol. 2011;724:69-77. https:// doi.org/10.1007/978-1-61779-055-3_4

25. Ru Y, Kechris KJ, Tabakoff B, Hoffman P, Radcliffe RA, Bowler R, et al. The multiMiR R package and database: integration of microRNA-target interactions along with their disease and drug associations. Nucleic Acids Res. 2014:42(17):e133. https://doi.org/10.1093/nar/gku631.

26. Dominici M, Le Blanc K, Mueller I, Slaper-Cortenbach I, Marini F, Krause D, et al. Minimal criteria for defining multipotent mesenchymal stromal cells. The International Society for Cellular Therapy position statement. Cytotherapy. 2006:8(4):315-7. https://doi.org/10.1080/14653240600855905.

27. Gilbane AJ, Denton CP, Holmes AM. Scleroderma pathogenesis: a pivotal role for fibroblasts as effector cells. Arthritis Res Ther. 2013;15(3):215. https:// doi.org/10.1186/ar4230.

28. Marangoni RG, Korman BD, Wei J, Wood TA, Graham LV, Whitfield ML, et al. Myofibroblasts in murine cutaneous fibrosis originate from adiponectinpositive intradermal progenitors. Arthritis Rheumatol. 2015;67(4):1062-73. https://doi.org/10.1002/art.38990.

29. Yamamoto T, Takagawa S, Katayama I, Yamazaki K, Hamazaki Y, Shinkai H, et al. Animal model of sclerotic skin. I: Local injections of bleomycin induce sclerotic skin mimicking scleroderma. J Invest Dermatol. 1999;112(4):456-62. https://doi.org/10.1046/j.1523-1747.1999.00528.x.

30. Liao N, Shi Y, Wang Y, Liao F, Zhao B, Zheng Y, et al. Antioxidant preconditioning improves therapeutic outcomes of adipose tissue-derived mesenchymal stem cells through enhancing intrahepatic engraftment efficiency in a mouse liver fibrosis model. Stem Cell Res Ther. 2020;11(1):237. https://doi.org/10.1186/s13287-020-01763-y.

31. Yu Y, Hu D, Zhou $Y$, Xiang H, Liu B, Shen L, et al. Human umbilical cord mesenchymal stem cell attenuates renal fibrosis via TGF- $\beta / S$ mad signaling pathways in vivo and in vitro. Eur J Pharmacol. 2020;883:173343. https://doi. org/10.1016/j.ejphar.2020.173343.

32. Lim JY, Ryu DB, Kim TW, Lee SE, Park G, Yoon HK, et al. CCL1 blockade alleviates human mesenchymal stem cell (hMSC)-induced pulmonary fibrosis in a murine sclerodermatous graft-versus-host disease (Scl-GVHD) model. Stem Cell Res Ther. 2020;11(1):254. https://doi.org/10.1186/s13287-02 0-01768-7.

33. Zhao FY, Cheng TY, Yang L, Huang YH, Li C, Han JZ, et al. G-CSF inhibits pulmonary fibrosis by promoting BMSC homing to the lungs via SDF-1/ CXCR4 chemotaxis. Sci Rep. 2020;10(1):10515. https://doi.org/10.1038/s41 598-020-65580-2.

34. Urbanelli L, Buratta S, Sagini K, Ferrara G, Lanni M, Emiliani C. Exosomebased strategies for diagnosis and therapy. Recent Pat CNS Drug Discov. 2015;10(1):10-27. https://doi.org/10.2174/1574889810666150702124059.

35. Gaire M, Magbanua Z, McDonnell S, McNeil L, Lovett DH, Matrisian LM. Structure and expression of the human gene for the matrix metalloproteinase matrilysin. J Biol Chem. 1994;269(3):2032-40. https://doi. org/10.1016/S0021-9258(17)42131-4.

36. El-Andaloussi S, Lee Y, Lakhal-Littleton S, Li J, Seow Y, Gardiner C, et al. Exosome-mediated delivery of siRNA in vitro and in vivo. Nat Protoc. 2012; 7(12):2112-26. https://doi.org/10.1038/nprot.2012.131.

37. Cheng $Y$, Zeng $\mathrm{Q}$, Han $\mathrm{Q}$, Xia W. Effect of $\mathrm{pH}$, temperature and freezingthawing on quantity changes and cellular uptake of exosomes. Protein Cell. 2019;10(4):295-9. https://doi.org/10.1007/s13238-018-0529-4.

38. Milano G, Biemmi V, Lazzarini E, Balbi C, Ciullo A, Bolis S, et al. Intravenous administration of cardiac progenitor cell-derived exosomes protects against doxorubicin/trastuzumab-induced cardiac toxicity. Cardiovasc Res. 2020; 116(2):383-92. https://doi.org/10.1093/cvr/cvz108.

39. Sun $L, X u R$, Sun $X$, Duan $Y$, Han $Y$, Zhao $Y$, et al. Safety evaluation of exosomes derived from human umbilical cord mesenchymal stromal cell. Cytotherapy. 2016;18(3):413-22. https://doi.org/10.1016/j.jcyt.2015.11.018.

40. Cheng L, Zhang K, Wu S, Cui M, Xu T. Focus on mesenchymal stem cellderived exosomes: opportunities and challenges in cell-free therapy. Stem Cells Int. 2017;2017:6305295. 
41. Chen TS, Arslan F, Yin Y, Tan SS, Lai RC, Choo AB, et al. Enabling a robust scalable manufacturing process for therapeutic exosomes through oncogenic immortalization of human ESC-derived MSCs. J Transl Med. 2011; 9(1):47. https://doi.org/10.1186/1479-5876-9-47.

42. Nedaeinia R, Manian M, Jazayeri MH, Ranjbar M, Salehi R, Sharifi M, et al. Circulating exosomes and exosomal microRNAs as biomarkers in gastrointestinal cancer. Cancer Gene Ther. 2017;24(2):48-56. https://doi. org/10.1038/cgt.2016.77.

43. Li J, Liu K, Liu Y, Xu Y, Zhang F, Yang H, et al. Exosomes mediate the cell-tocell transmission of IFN-a-induced antiviral activity. Nat Immunol. 2013;14(8): 793-803. https://doi.org/10.1038/ni.2647.

44. Liu W, Rong Y, Wang J, Zhou Z, Ge X, Ji C, et al. Exosome-shuttled miR-216a-5p from hypoxic preconditioned mesenchymal stem cells repair traumatic spinal cord injury by shifting microglial M1/M2 polarization. J Neuroinflammation. 2020;17(1):47. https://doi.org/10.1186/ s12974-020-1726-7.

45. Xin L, Lin X, Zhou F, Li C, Wang X, Yu H, et al. A scaffold laden with mesenchymal stem cell-derived exosomes for promoting endometrium regeneration and fertility restoration through macrophage immunomodulation. Acta Biomater. 2020;113:252-66. https://doi.org/10.101 6/j.actbio.2020.06.029.

46. Zanotti S, Gibertini S, Blasevich F, Bragato C, Ruggieri A, Saredi S, et al. Exosomes and exosomal miRNAs from muscle-derived fibroblasts promote skeletal muscle fibrosis. Matrix Biol. 2018;74:77-100. https://doi.org/10.1016/j. matbio.2018.07.003.

47. Zhou B, Zuo XX, Li YS, Gao SM, Dai XD, Zhu HL, et al. Integration of microRNA and mRNA expression profiles in the skin of systemic sclerosis patients. Sci Rep. 2017;7(1):42899. https://doi.org/10.1038/srep42899.

48. Dees C, Distler JH. Canonical Wnt signalling as a key regulator of fibrogenesis - implications for targeted therapies? Exp Dermatol. 2013. 22(11):710-3. https://doi.org/10.1111/exd.12255.

49. Wei J, Melichian D, Komura K, Hinchcliff M, Lam AP, Lafyatis R, et al. Canonical Wnt signaling induces skin fibrosis and subcutaneous lipoatrophy: a novel mouse model for scleroderma? Arthritis Rheum. 2011; 63(6):1707-17. https://doi.org/10.1002/art.30312.

50. Lee $H$, Han S, Kwon CS, Lee D. Biogenesis and regulation of the let-7 miRNAs and their functional implications. Protein Cell. 2016;7(2):100-13. https://doi.org/10.1007/s13238-015-0212-y.

51. Angelou CC, Wells AC, Vijayaraghavan J, Dougan CE, Lawlor R, Iverson $E$, et al. Differentiation of pathogenic Th17 cells is negatively regulated by Let-7 microRNAs in a mouse model of multiple sclerosis. Front Immunol. 2019;10:3125.

52. Bernstein $\mathrm{DL}$, Rom S. Let-7 $\mathrm{g}^{*}$ and miR-98 reduce stroke-induced production of proinflammatory cytokines in mouse brain. Front Cell Dev Biol. 2020;8: 632. https://doi.org/10.3389/fcell.2020.00632.

53. Pobezinsky LA, Etzensperger R, Jeurling S, Alag A, Kadakia T, McCaughtry TM, et al. Let-7 microRNAs target the lineage-specific transcription factor PLZF to regulate terminal NKT cell differentiation and effector function. Nat Immunol. 2015;16(5):517-24. https://doi.org/10.1038/ni.3146.

54. Cushing L, Kuang PP, Qian J, Shao F, Wu J, Little F, et al. Lü J: miR-29 is a major regulator of genes associated with pulmonary fibrosis. Am Respir Cell Mol Biol. 2011;45(2):287-94. https://doi.org/10.1165/rcmb.201 0-0323OC.

55. Pandit KV, Milosevic J, Kaminski N. MicroRNAs in idiopathic pulmonary fibrosis. Transl Res. 2011;157(4):191-9. https://doi.org/10.1016/j.trsl.2011. 01.012.

56. Emmrich S, Rasche M, Schöning J, Reimer C, Keihani S, Maroz A, et al. miR-99a/100 125b tricistrons regulate hematopoietic stem and progenitor cell homeostasis by shifting the balance between TGF $\beta$ and Wnt signaling. Genes Dev. 2014;28(8):858-74. https://doi.org/10.1101/ga d.233791.113.

57. Wei J, Fang F, Lam AP, Sargent JL, Hamburg E, Hinchcliff ME, et al. Wnt/ beta-catenin signaling is hyperactivated in systemic sclerosis and induces Smad-dependent fibrotic responses in mesenchymal cells. Arthritis Rheum. 2012;64(8):2734-45. https://doi.org/10.1002/art.34424.

58. Gillespie J, Ross RL, Corinaldesi C, Esteves F, Derrett-Smith E, McDermott MF, et al. Transforming growth factor beta activation primes canonical Wnt signaling through down-regulation of Axin-2. Arthritis Rheumatol. 2018; 70(6):932-42. https://doi.org/10.1002/art.40437.

59. Kawakita A, Yanamoto S, Yamada S, Naruse T, Takahashi H, Kawasaki G, et al. MicroRNA-21 promotes oral cancer invasion via the $\mathrm{Wnt} / \beta$-catenin pathway by targeting DKK2. Pathol Oncol Res. 2014;20(2):253-61. https://doi.org/10.1 007/s12253-013-9689-y.

60. Tan M, Wu J, Cai Y. Suppression of Wnt signaling by the miR-29 family is mediated by demethylation of WIF-1 in non-small-cell lung cancer. Biochem Biophys Res Commun. 2013;438(4):673-9. https://doi.org/10.1016/j. bbrc.2013.07.123.

\section{Publisher's Note}

Springer Nature remains neutral with regard to jurisdictional claims in published maps and institutional affiliations.
Ready to submit your research? Choose BMC and benefit from:

- fast, convenient online submission

- thorough peer review by experienced researchers in your field

- rapid publication on acceptance

- support for research data, including large and complex data types

- gold Open Access which fosters wider collaboration and increased citations

- maximum visibility for your research: over $100 \mathrm{M}$ website views per year

At BMC, research is always in progress.

Learn more biomedcentral.com/submissions 